\title{
Implementasi Circular Hough Transform untuk Pendeteksian Kebohongan pada Anak melalui Pergerakan Kornea Mata
}

\author{
ASEP NANA HERMANA, IRMA AMELIA DEWI, RHYALDI YUNUS
}

Teknik Informatika, Institut Teknologi Nasional Bandung

Email: asep_nana_h@yahoo.com

\begin{abstract}
ABSTRAK
Pergerakan kornea mata kearah kanan merupakan ekspresi respon yang tidak disadari oleh anak saat mereka sedang berbohong. Pergerakan tersebut dapat dijadikan salah satu acuan untuk pendeteksian kebohongan. kornea mata dapat dideteksi menggunakan metode Circular Hough Transform. proses Selanjutnya adalah menentukan pergerakan kornea mata dengan membandingkan nilai pixel dari satu frame dengan frame lainnya. Jika nilai pixel pada frame berikutnya lebih besar dari nilai awal, maka mengindikasi adanya pergerakan kornea mata ke arah kanan, sebaliknya saat pergerakan nilai pixel lebih kecil dari nilai awal maka pergerakan mata mengarah kiri. pengujian dilakukan dalam satu sesi wawancara, jika adanya pergerakan kornea ke arah kanan mencapai 60\%, maka dapat disimpulkan terdapat kecenderungan berbohong. Tingkat akurasi sistem yang diperoleh berdasarkan pengujian terhadap 50 anak didapatkan presentase sebesar $52 \%$.
\end{abstract}

Kata kunci: Pergerakan Mata, Tanda Bohong, Circular Hough Transform

\begin{abstract}
The movement of the cornea to the right is an unconscious response when someone is lying. This movement can be used as a reference for detecting lies. Corneas can be detected using the Hough Transform Circular. Furthermore the process is to determine the movement of corneas by comparing the pixel values from one frame to another frame. If the pixel value in the next frame is greater than the initial value, it indicates the movement of the cornea to the right, on the contrary when the pixel value is smaller than the initial value then the eye movement is left. The testing was conducted in one interview session, if there was a corneal movement to the right reaching $60 \%$, it can be concluded that there was a tendency to lie. The level of system accuracy obtained based on testing of 50 children obtained a percentage of $52 \%$.
\end{abstract}

Keywords: Eye Movement, Sign of Lie, Circular Hough Transform 


\section{PENDAhUlUAN}

Pergerakan arah mata seorang anak dapat mengekspresikan berbagai macam rasa atau ekspresi, salah satunya ekspresi yang terlihat adalah ketika berbohong, yang dilihat dengan pergerakan mata mengarah kanan.Saat anak lebih condong mengarahkan mata ke kanan dengan persentase $60 \%$ pada sebuah percakapan maka anak tersebut memiliki kecenderungan untuk berbohong (Bandler \& Grinder, 1979).

Dengan adanya ciri pergerakan mata pada saat berbohong maka implementasi pergerakan dapat diimplementasikan untuk sistem pendeteksian kebohongan pada anak yang berfungsi untuk mengetahui tingkat kebohongan (Martani, 2012). Haar cascade adalah metode untuk menemukan area mata pada gambar yang didapat dari pencocokan data latih dengan data uji. Dalam teknik haar cascade dibutuhkan proses pencocokan untuk mengetahui nilai kecocokan terbesar. Dalam proses pencocokan digunakan penyisipan citra dengan menggunakan rumus integral image yang diteruskan pada fitur haar (Sajati, 2015). Proses pendeteksian lingkaran digunakan metode circular hough transform, dimana circluar hough transform adalah proses pengambilan keputusan berdasarkan voting terbanyak untuk membuat lingkaran pada citra (Pedersen, 2007) (Rizon, et al., 2005).

Aplikasi dibuat menggunakan data masukan berupa video secara realtime yang di implementasi kepada anak dimasa dewasa awal yaitu usia 10 tahun sampai 15 tahun yang tidak memiliki kelainan pada mata.

\section{METODOLOGI PENELITIAN}

Pendeteksian citra diaplikasikan sebagai sistem pendeteksian kebohongan dengan menggunakan kornea mata. Pendeteksian kornea mata memiliki dua proses pada saat melakukan pendeteksian, yaitu proses pendeteksian area mata dan proses pendeteksian lingkaran kornea pada mata yang dilanjutkan pada proses pengambilan kesimpulan seperti tampak pada Gambar 1.

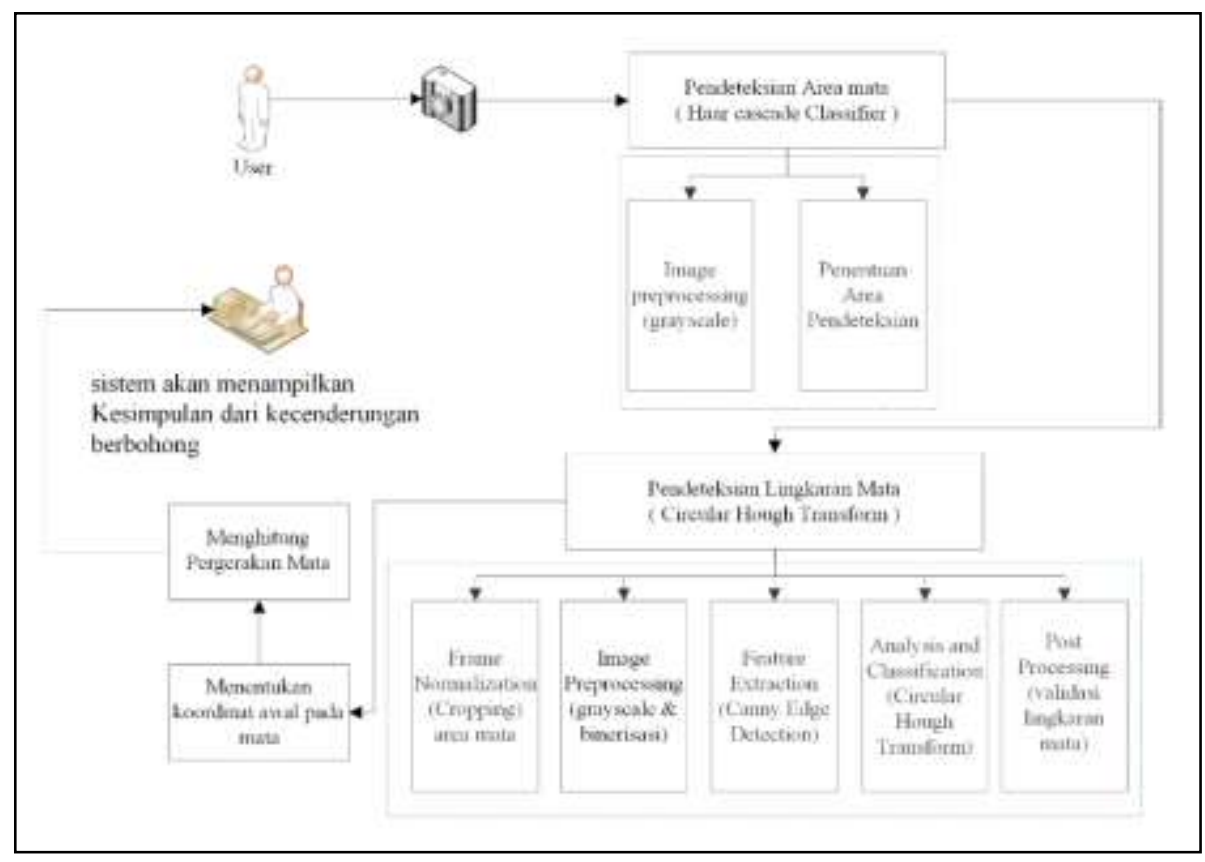

Gambar 1. Alur Sistem 
Proses pendeteksian area mata merupakan proses awal saat melakukan pengolahan untuk mendapatkan area mata. Pendeteksian area mata dilakukan menggunakan metode haar cascade untuk mendapatkan area mata yang dimulai dengan proses image processing berupa grayscale yang merubah citra asli yang masih berupa RGB menjadi abu-abu yang ditunjukan pada Persamaan 1.

Dimana:

$$
f_{0}(x, y)=\frac{f_{i}^{R}(x, y)+f_{i}^{G}(x, y)+f_{i}^{B}(x, y)}{3}
$$

$f_{o}(x, y)=$ Nilai citra abu-abu pada koordinat ke $x, y$

$f_{i}^{R}(x, y)=$ Nilai warna red pada koordinat ke $x, y$

$f_{i}^{G}(x, y)=$ Nilai warna green pada koordinat ke $x, y$

$f_{i}^{B}(x, y)=$ Nilai warna blue pada koordinat ke $x, y$

Citra abu-abu yang didapat dilakukan perhitungan integral image yang bertujuan menangkap gambar bergerak pada citra yang terdapat pada Persamaan 2. Dari hasil pencocokan data diambil citra yang menyerupai data latih sehingga sistem menampilkan area mata yang digunakan untuk pendeteksian lingkaran kornea pada mata (Munir, 2004).

$$
s(x, y)=s(x, y)+s(x-1, y)+s(x, y-1)-s(x-1, y-1)
$$

Dimana:

$s \quad=$ Nilai pixel integral image yang terdapat pada koordinat $x$ dan $y$

$x=$ Nilai koordinat pada posisi $x$

$y=$ Nilai koordinat pada posisi $y$

Pengolahan citra dilakukan dengan circular hough transform yang meliputi beberapa proses untuk mendukung pendeteksian, dimulai dengan menormalisasi citra dengan cropping yang bertujuan untuk membuat jangkauan pendeteksian menjadi lebih sempit dengan mengambil area sekitar mata yang terdapat pada Persamaan 3 (Marvin \& Prijono, 2007).

dimana:

$$
\begin{array}{ll}
x^{\prime}=x-x_{L} & \text { untuk } x=x_{L} \text { sampai } x_{R} \\
y^{\prime}=y-y_{T} & \text { untuk } y=y_{T} \text { sampai } y_{B}
\end{array}
$$

$x=$ koordinat indeks $x$

$x_{L} \quad=$ koordinat $x$ arah kiri

$x_{R} \quad=$ koordinat $x$ arah kanan

$y=$ koordinat indeks $y$

$y_{L} \quad=$ koordinat $y$ arah kiri

$y_{R} \quad=$ koordinat $y$ arah kanan

Citra yang telah dipotong dideteksi garis tepi menggunakan canny edge detection untuk mencari garis tepi dari citra masukan dengan perhitungan noise reduction Persamaan (4) dan finding gradient Persamaan (5).

Dimana:

$$
H_{i, j}=\frac{1}{2 \pi \sigma^{2}} \exp \left(-\frac{(i-k-1)^{2}+(j-k-1)^{2}}{2 \sigma^{2}}\right)
$$

$\sigma \quad=$ standard deviasi

$(i, j)=$ elemen matriks pada posisi $(i, j)$

$\mathrm{k}=$ indeks matriks 
Proses selanjutnya adalah mendeteksi keberadaan lingkaran dengan Circular Hough Transform dengan mencari jari-jari dengan menggunakan Persamaan (5) dari masing-masing garis tepi yang didapatkan oleh Canny (Marvin \& Prijono, 2007).

$$
r=\sqrt{\left(x-x_{n}\right)^{2}+\left(y-y_{n}\right)^{2}}
$$

\section{Dimana:}

$$
\begin{array}{ll}
\mathrm{r} & =\text { jari-jari } \\
\mathrm{x} & =\text { jumlah baris pada } \mathrm{x} \\
\mathrm{x}_{\mathrm{n}} & =\text { indeks matrik } \mathrm{x} \text { ke } \mathrm{n} \\
\mathrm{y} & =\text { jumlah baris pada } \mathrm{y} \\
\mathrm{y}_{\mathrm{n}} & =\text { indeks matrik } \mathrm{y} \text { ke } \mathrm{n}
\end{array}
$$

Jari-jari digunakan untuk mencari ruang parameter Persamaan (6) atau luas lingkaran dari masing-masing titik (Munir, 2004). Untuk mendapatkan lingkaran sistem melakukan voting dengan mengambil titik jari-jari yang terbanyak hingga lingkaran ditemukan. Lingkaran terbesar yang didapat diasumsikan sebagai kornea mata.

$$
\begin{aligned}
& x=a+r \cos q \\
& y=b+r \sin q
\end{aligned}
$$

dimana:

$a=$ Nilai koordinat $x$ ke $n$

$b \quad=$ Nilai koordinat $y$ ke $n$

$r \quad=$ Jari - jari

$q \quad=$ Gradient kemiringan

Perhitungan koordinat awal dilakukan setelah lingkaran kornea mata didapatkan untuk menghitung arah pergerakan mata dengan membandingkan nilai pixe/dari satu frame dengan frame lainnya. Saat pergerakan nilai pixel lebih dari atau kurang dari nilai ambang yang ditentukan maka terjadi pergerakan pada mata yang tampak pada Gambar 2.

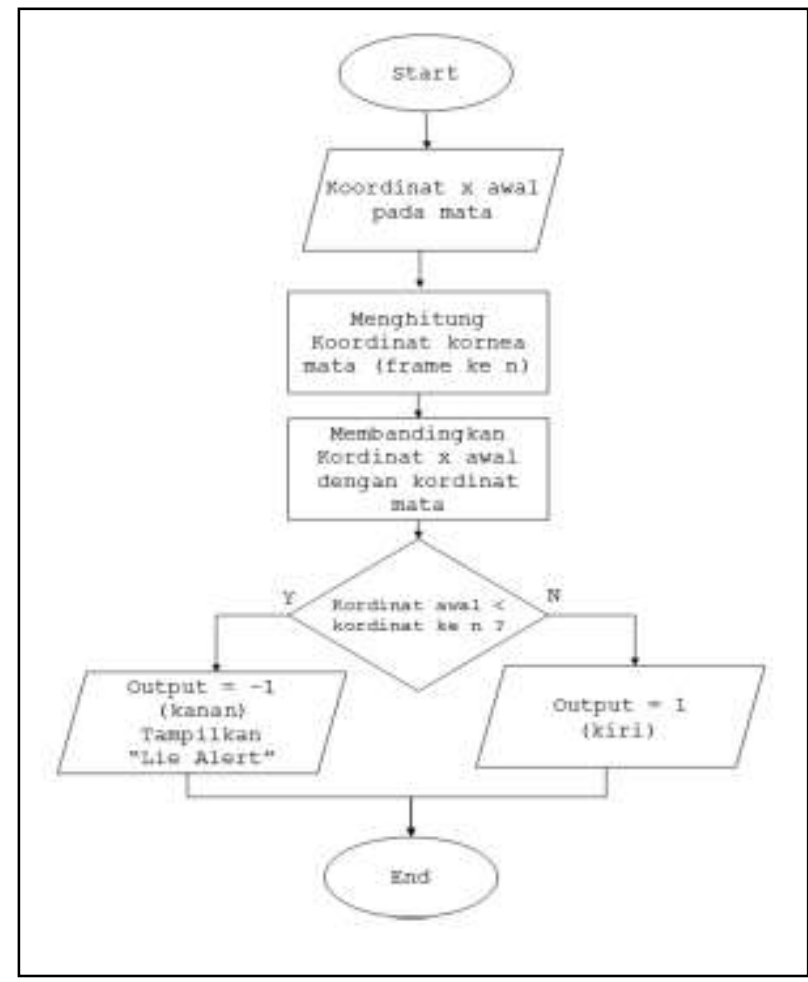

Gambar 2. Menghitung pergerakan mata 
Ketika pergerakan arah mata mengarah kanan terdapat indikator "lie detection". Dari semua pergerakan arah mata yang didapat, diambil kesimpulan apabila dalam persentase pergerakan $60 \%$ kearah kanan maka anak ada kecenderungan berbohong.

\section{ANALISIS DAN PEMBAHASAN}

Aplikasi pendeteksian mempunyai dua proses yaitu pendeteksian area mata dan pendeteksian lingkaran kornea pada mata yang terdapat pada Gambar 1.

\section{Perekaman Citra}

Proses awal dilakukan perekaman pendeteksian dengan menggunakan sebuah kamera. Perekaman berlangsung dengan adanya objek untuk dideteksi. Berikut adalah tahapan studi kasus pada aplikasi pendeteksian kebohongan pada anak menggunakan metode Circular Hough Transform. Dari $640 \times 480$ pixel citra yang dideteksi, diambil citra $5 \times 5$ pixel sebagai asumsi yang terdapat pada Gambar 3.

\begin{tabular}{|c|c|c|c|c|c|}
\hline$(x, y)$ & 0 & 1 & 2 & 3 & 4 \\
\hline \multirow{3}{*}{0} & $\mathrm{R}=60$ & $R=90$ & $R=50$ & $R=50$ & $R=50$ \\
\hline & $G=50$ & $G=50$ & $G=40$ & $G=90$ & $G=60$ \\
\hline & $B=70$ & $B=30$ & $8=60$ & $B=20$ & $B=30$ \\
\hline \multirow{3}{*}{1} & $R=50$ & $R=20$ & $R=40$ & $R=10$ & $R=50$ \\
\hline & $G=60$ & $G=40$ & $G=50$ & $G=80$ & $G=70$ \\
\hline & $B=40$ & $B=50$ & $8=30$ & $B=70$ & $B=50$ \\
\hline \multirow{3}{*}{2} & $R=40$ & $R=40$ & $R=90$ & $R=10$ & $R=40$ \\
\hline & $G=70$ & $G=90$ & $G=90$ & $G=50$ & $G=30$ \\
\hline & $B=30$ & $B=20$ & $8=40$ & $B=80$ & $8=70$ \\
\hline \multirow{3}{*}{3} & $R=20$ & $R=40$ & $R=40$ & $R=30$ & $R=50$ \\
\hline & $G=90$ & $\mathrm{G}=60$ & $G=50$ & $G=30$ & $\mathrm{G}=40$ \\
\hline & $B=100$ & $B=50$ & $8=50$ & $B=10$ & $B=90$ \\
\hline \multirow{3}{*}{4} & $R=40$ & $R=40$ & $R=195$ & $R=50$ & $A=60$ \\
\hline & $G=60$ & $G=30$ & $G=10$ & $G=40$ & $G=60$ \\
\hline & $B=30$ & $B=50$ & $B=220$ & $B=30$ & $B=50$ \\
\hline
\end{tabular}

Gambar 3 Asumsi citra 5x5

\section{Pendeteksian Daerah Mata}

Proses pendeteksian mata ini diperlukan untuk mempersempit area yang di deteksi selanjutnya. Proses pendeteksian ini menggunakan metode Haar Cascade. Haar cascade bekerja dengan cara membandingkan citra asli dengan citra data latih (Sajati, 2015). Citra yang diambil dalam bentuk RGB dirubah menjadi abu-abu dengan grayscale yang terdapat pada persamaan 1 . Contoh perhitungan grayscale pada pixel $(0,0)$ sebagai berikut:

$$
f_{0}(0,0)=\frac{60+50+10}{3}=60
$$

Berikut hasil perhitungan semua pixel yang telah dilakukan proses grayscale 
Tabel 1 Hasil grayscale

\begin{tabular}{|c|c|c|c|c|c|}
\hline$(\mathrm{x}, \mathrm{y})$ & 0 & 1 & 2 & 3 & 4 \\
\hline 0 & 60 & 56.7 & 33.3 & 46.7 & 46.7 \\
\hline 1 & 50 & 40 & 46.7 & 56.7 & 56.7 \\
\hline 2 & 46.7 & 50 & 73.3 & 50 & 46.7 \\
\hline 3 & 70 & 46.7 & 50 & 26.7 & 60 \\
\hline 4 & 43.3 & 40 & 141.7 & 40 & 56.7 \\
\hline
\end{tabular}

\section{Pendeteksian Lingkaran Mata}

Proses pendeteksian lingkaran mata kornea menggunakan metode circular hough transform. Didalam metode terdapat berbagai metode pendukung untuk memaksimalkan pendeteksian. Citra dinormalisasi dengan proses cropping sehingga memfokuskan pendeteksian pada pixel (Anwariningsih, Arifin, \& Yuniarti, 2010).

$$
\begin{aligned}
\mathrm{W}^{\prime} & =\mathrm{x}_{\mathrm{R}}-\mathrm{x}_{\mathrm{L}} \\
& =4-1 \\
& =3 \\
\mathrm{~h}^{\prime} & =\mathrm{y}_{\mathrm{B}}-\mathrm{y}_{\top} \\
& =4-1 \\
& =3
\end{aligned}
$$

Proses cropping citra menghasilkan citra dengan $3 \times 3$ pixel

Tabel 2. hasil cropping citra

\begin{tabular}{|c|c|c|c|}
\hline$(\mathrm{x}, \mathrm{y})$ & 0 & 1 & 2 \\
\hline 0 & 153.3 & 183.3 & 223.3 \\
\hline 1 & 186.7 & 193.3 & 183.3 \\
\hline 2 & 186.7 & 216.7 & 196.7 \\
\hline
\end{tabular}

Citra yang masih pada nilai abu abu menjadi nilai hitam putih. Dari beberapa percobaan threeshold yang digunakan pada proses binerisasi adalah 190 sehingga hasil dari proses adalah

Tabel 3. citra hitam putih

\begin{tabular}{|c|c|c|c|c|c|}
\hline$(\mathrm{x}, \mathrm{y})$ & 0 & 1 & 2 & 3 & 4 \\
\hline 0 & 1 & 1 & 1 & 1 & 1 \\
\hline 1 & 1 & 1 & 1 & 0 & 1 \\
\hline 2 & 1 & 1 & 0 & 1 & 1 \\
\hline 3 & 1 & 1 & 0 & 0 & 1 \\
\hline 4 & 1 & 1 & 1 & 1 & 1 \\
\hline
\end{tabular}

Pendeteksian garis tepi menggunakan metode Canny dari matrik yang telah diproses sebelumnya didapatkan yang memiliki nilai 1 adalah pada koordinat $(1,1),(1,2),(2,1),(2,3)$, $(3,1)$. Koordinat tersebut dihitung dengan Persamaan 4 untuk Noise reduction 


$$
\begin{aligned}
H_{(1,1)}=\frac{1}{2(3.14) x(1.4)^{2}} \exp \left(-\frac{-(1-5-1)^{2}+-(1-5-1)^{2}}{2(1,4)^{2}}\right) & \\
= & \frac{1}{12.3} \exp \left(-\frac{25+25}{3.94}\right) \\
= & \frac{1}{12.3} \exp \left(-\frac{50}{3.94}\right) \\
= & \frac{1}{12.3} \exp (-12.7) \\
& =1,03
\end{aligned}
$$

Hasil dari Noise reduction berupa matrik yang digunakan untuk tahapan finding gradient dengan menggunakan Persamaan 7

$$
\left[\begin{array}{c}
1.030 .840 .7 \\
0.840 .650 .51 \\
0.690 .510 .37
\end{array}\right]
$$

$$
\begin{array}{r}
G x=(0,7+2(0,51)+0,37)-(1,03+2(0,84)+0,69) \\
=-1,31 \\
\begin{array}{l}
G y=(1,03+2(0,84)+0,7)-(0,69+2(0,51)+0,37) \\
=1,31
\end{array} \\
G=1,62
\end{array}
$$

Dimana $\mathrm{G}_{\mathrm{x}}$ dan $\mathrm{G}_{\mathrm{y}}$ adalah gradien pada masing-masing arah $x$ dan $y$, kemudian ditentukan arah tepian yang ditentukan dengan menggunakan Persamaan 8.

$$
\begin{aligned}
\theta(\mathrm{x}, \mathrm{y}) & =\tan ^{-1}(1,31 /-1,31) \\
& =\tan ^{-1}(-1) \\
& =57.289
\end{aligned}
$$

Hasil tepian bernilai 57,289 dan kategori tersebut masuk dalam kategori $45^{\circ}$

Dari koordinat dan arah tepi yang didapat dihitung jari jari dari seluruh matrik citra dengan metode circular hough transform dengan Persamaan 5

$$
\begin{gathered}
r(1,1)=\sqrt{(5-1)^{2}+(5-1)^{2}} \\
=\sqrt{16+16} \\
=\sqrt{32}
\end{gathered}
$$

Dari nilai jari jari yang diperoleh dilakukan perhitungan ruang parameter untuk citra dengan Persamaan 6 yang merupakan nilai arah tepi

$$
\begin{aligned}
&(1,1) x_{1}=1+2 \cos 45^{\circ} \\
&= 3 \times \frac{\sqrt{2}}{2} \\
&=2,12 \quad=3 \times \frac{\sqrt{2}}{2} \\
& y_{1}=1+2 \sin 45^{\circ} \\
&=2,12
\end{aligned}
$$$$
(1,2) x_{1}=1+2 \cos 45^{\circ}
$$ 
$=2,12$

$$
=3 \times \frac{\sqrt{2}}{2}
$$

$$
\begin{array}{r}
y_{2}=2+2 \sin 45^{\circ} \\
=4 \times \frac{\sqrt{2}}{2}
\end{array}
$$

$=2,82$

Ruang parameter berfungsi untuk menentukan luas lingkaran yang dibuat pada masing masing koordinat seperti tampak pada Gambar 4

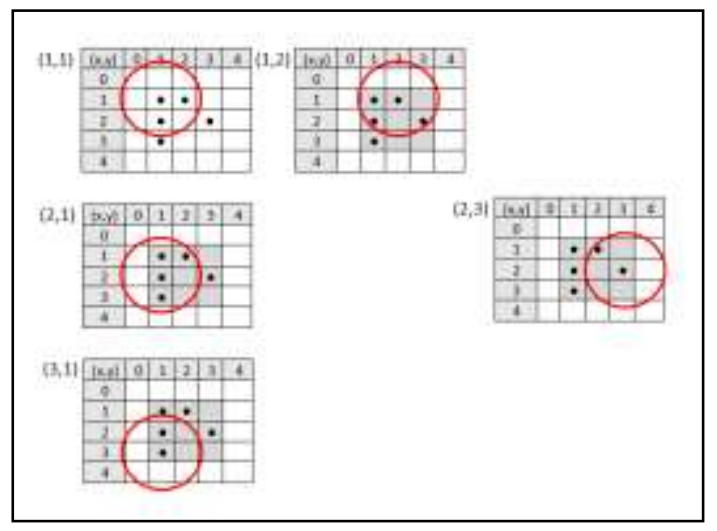

\section{Gambar 4 Penggambaran masing masing ruang parameter}

Dari masing masing pixe/ yang telah digambar, selanjutnya sistem melakukan voting untuk mendapatkan pusat lingkaran asli dengan cara membandingkan pixe/ yang sering muncul bersingungan dari masing masing titik.

Hasil perbandingan dari semua pixe/ yang sering muncul adalah $(2,2)$ dengan kemunculan pixe/ pada 4 titik area yang terdapat pada Gambar 5

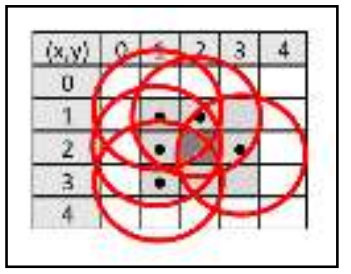

\section{Gambar 5. Pengambaran titik pusat}

Dari hasil voting yang didapat dilakukan perhitungan parameter lingkaran baru pada koordinat $(2,2)$ yang terdapat pada Gambar 6 yang ditetapkan sebagai lingkaran mata

$$
\begin{aligned}
(2,2) x_{2}=2 & +2 \cos 45^{\circ} \\
= & 4 x \frac{\sqrt{2}}{2} \\
y_{2}=2+2 & \cos 45^{\circ} \\
= & 4 x \frac{\sqrt{2}}{2} \\
=2,82 &
\end{aligned}
$$




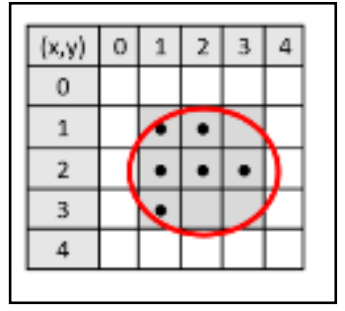

\section{Gambar 6. Lingkaran baru}

Output dari pendeteksian lingkaran berupa pemeriksa konsistensi hubungan antara satu frame ke frame yang lain sehingga sistem dapat memastikan bahwa lingkaran yang didapat adalah lingkaran kornea mata.

\section{Menghitung Pergerakan Mata}

Koordinat pergerakan mata dihitung dari satu frame ke frame lain dengan beberapa kondisi untuk mendapatkan output. Output yang didapat apabila mata terdeteksi ke kanan adalah -1 sedangkan ke kiri adalah 1 . Output yang didapat pada proses ini akan dikumpulkan hingga aplikasi dihentikan.

Untuk dapat mengetahui pergerakan mata mengarah ke kanan atau ke kiri, sistem melakukan pembandingkan antar frame. Tabel 4 merupakan implementasi perbandingan pergerakan sesuai pada koordinat masing-masing.

Tabel 4. Pergerakan mata

\begin{tabular}{|l|l|l|l|l|}
\hline $\begin{array}{c}\text { frame } \\
\text { ke }\end{array}$ & $\begin{array}{c}\text { koordinat } \\
\text { awal }\end{array}$ & \multicolumn{1}{|c|}{ Status } & Arah & \multicolumn{1}{|c|}{ Alert } \\
\hline 4 & $(4,4)$ & & & \\
\hline 5 & $(4,4)$ & & & \\
\hline 6 & $(4,6)$ & Terjadi Pergerakan & kanan & Lie Alert \\
\hline 7 & $(4,4)$ & Terjadi Pergerakan & kiri & \\
\hline 8 & $(4,1)$ & Terjadi Pergerakan & kiri & \\
\hline 9 & $(4,4)$ & Terjadi Pergerakan & kanan & Lie Alert \\
\hline 10 & $(4,7)$ & Terjadi Pergerakan & kanan & Lie Alert \\
\hline
\end{tabular}

\subsection{Pengujian Sistem}

Pengujian yang dilakukan terdiri dari pengujian alpha dan beta. Pada pengujian alpha dilakukan pada 30 orang yang diambil secara acak untuk mencari pengaturan pada kondisi berbeda, dimana kondisinya sebagai berikut:
a. Pendeteksian mata berdasarkan jarak
b. Pendeteksian mata berdasarkan intensitas cahaya
c. Pendeteksian pergerakan mata berdasarkan jarak
d. Pendeteksian pergerakan mata berdasarkan intensitas cahaya

Hasil pengaturan dan kondisi dari pengujian alpha digunakan pada pengujian beta seperti terlihat pada Gambar 7 


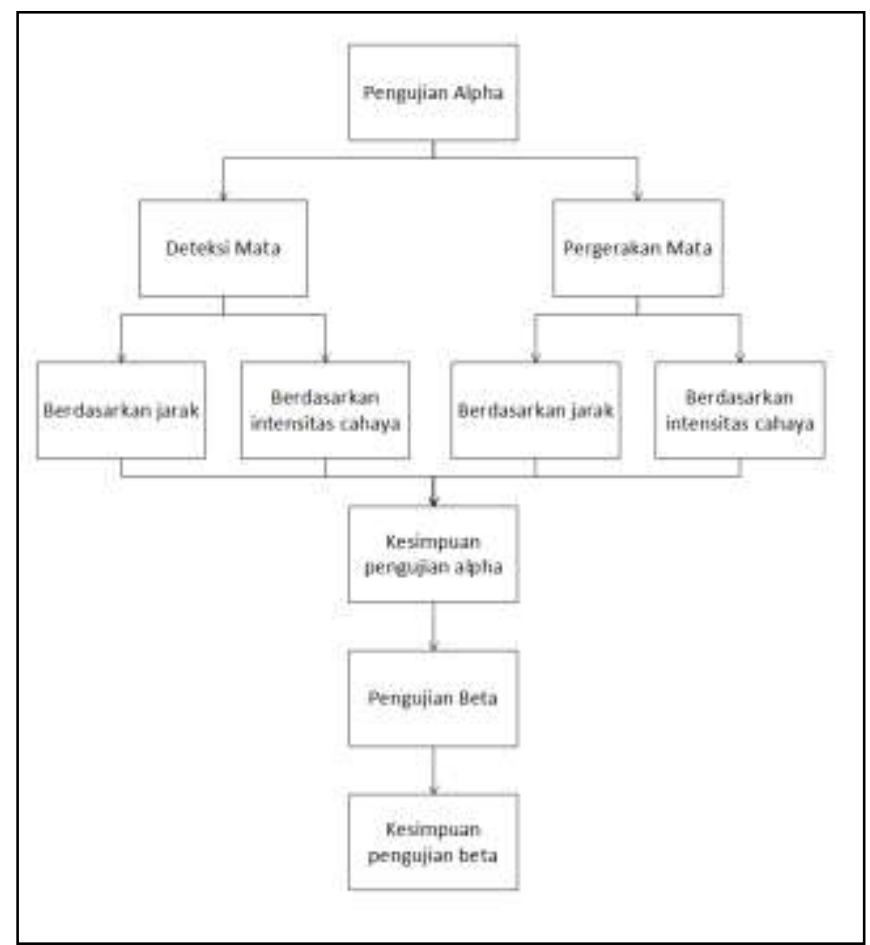

Gambar 7. Skenario pengujian

Dari hasil pengujian alpha didapatkan jarak ideal untuk melakukan deteksi mata dan pergerakan mata adalah $50 \mathrm{~cm}$ sampai dengan $100 \mathrm{~cm}$ dengan intensitas cahaya ideal adalah 10lux sampai dengan 1000lux.

Pengujian beta dilakukan pada 50 orang anak dengan beragam umur yang dimulai dari 10 tahun sampai 15 tahun. Kesimpulan sistem yang di dapat dalam pengujian ini juga melibatkan kesimpulan yang dibuat oleh psikolog. Psikolog melalukan pendampingan pada saat proses pendeteksian kobohongan yang bertujuan untuk mengawasi dan memvalidasi sistem. Pada Tabel 5 merupakan hasil pengujian pada anak.

Tabel 5. Hasil Pengujian

\begin{tabular}{|c|c|c|c|}
\hline No & Pengujian & $\begin{array}{c}\text { Banyak } \\
\text { Pengujian }\end{array}$ & $\begin{array}{c}\text { persentase (jumlah pengujian/banyak } \\
\text { pengujian x 100) }\end{array}$ \\
\hline 1 & pengujian yang sesuai & 26 & $52 \%$ \\
\hline 2 & $\begin{array}{c}\text { pengujian yang tidak } \\
\text { sesuai }\end{array}$ & 24 & $48 \%$ \\
\hline \multicolumn{2}{|c|}{ Jumlah } & 50 & $100 \%$ \\
\hline
\end{tabular}

Tingkat kesuksesan sistem mendeteksi keberadaan mata dan pergerakan mata mencapai $100 \%$, sedangkan tingkat kesuksesan sistem pada pengaplikasi deteksi kebohongan pada semua anak mencapai $52 \%$.

\section{KESIMPULAN}

Pendeteksian keberadaan mata pada struktur wajah dengan metode circular hough transform dapat digunakan dengan tingkat keberhasilan mencapai 100\%. Sedangkan untuk implementasian pergerakan kebohongan tidak akurat karena ketidak sesuaian output sistem dengan diagnosa psikolog dengan tingkat akurasi mencapai $52 \%$. 


\section{DAFTAR RUJUKAN}

Bandler , R., \& Grinder, J. (1979). Frogs into Princes: Neuro Linguistic Programming. Moab,Utah: Real People Press.

Martani, W. (2012). Metode Simulasi dan Perkembangan Emosi Anak Usia Dini. Yogyakarta: Universitas Gajah Mada.

Sajati, H. (2015, September 17). Deteksi Obyek Menggunakan Haar Cascade Classifier. Diambil kembali dari Let share our knowledge: http://jati.stta.ac.id/2015/09/deteksi-obyekmenggunakan-haar-cascade.html

Pedersen, S. J. (2007). Circular Hough Transform. Aalborg University.

Rizon, M., Yazid, H., Saad, P., Shakaff, A. Y., Saad, A. R., Sugisaka, M., . . . Karthigayan, M. (2005). Object detection using Circular Hough Transform. American Journal of Applied Sciences 2, 1606-1609.

Munir, R. (2004). Pengolahan Citra Digital. Bandung: Informatika.

Marvin, W. C., \& Prijono, A. (2007). Pengolahan Citra Digital Menggunakan Matlab. Bandung: Informatika.

Anwariningsih, S. H., Arifin, A. Z., \& Yuniarti, A. (2010). Estimasi Bentuk Structuring Element Berdasar Representasi Obyek. Jurnal Ilmiah Kursor, Vol 5 No. 3, 157-165. 